\title{
A Case Study of Two Groups of A1 Level Students in English
}

\author{
Avramidou Domna \\ English language teacher \\ BA in English language and literature in Aristotle University \\ MA in the Teaching of English as a Foreign/international language in Hellenic Open \\ University \\ E-mail: domnaavramidou@yahoo.gr
}

Makrina Zafiri

Permanent at the Aristotle University of Thessaloniki,

Office of Foreign Languages,

Teacher Trainer, ASPAITE, Thessaloniki,

Academic Associate at the Hellenic Open University,

MA Program in the Teaching of English as a Foreign/International Language

E-mail:m_nzafiri@yahoo.gr

Received: September 11, 2018 Accepted: November 1, 2018 Published: November 4, 2018

doi:10.5296/elr.v4i2.13640

URL: https://doi.org/10.5296/elr.v4i2.13640

\begin{abstract}
This study attempts to examine differentiated instruction and its implications in the teaching of oracy skills to young EFL learners. Within this aim, the EFL educational context investigated upon, was a private language centre in Greece where differentiated teaching approaches were applied to enhance students' oral and aural skills through the implementation of a task-based pedagogical intervention. Two groups of monolingual Greek students, were tested in English through a pre-test, which was of an A1 level, according to the Common European Framework of Reference for Languages (CEFR). There was a sample of eight students $(\mathrm{N}=8)$ in the control group and eight students $(\mathrm{N}=8)$ in the experimental group. The control group was taught through a conventional coursebook-based syllabus, whereas the
\end{abstract}


experimental group was taught through differentiated instruction. The comparison between the two groups revealed that the performance achieved by the students of the experimental group was significantly higher. The results, of this research, suggest that the pedagogical intervention used in the experimental group aided the development of students' oral and aural skills.

Keywords: Young learners, Oral and aural skills, Differentiated teaching, Case study

\section{Introduction}

Effective language teaching, especially when it comes to young learners, requires an environment that is supportive of change. It is commonly known that teaching decisions depend, amongst other things, on the interplay of individual beliefs and values, which are shaped by previous education and training, and the norms and values of the contexts in which they work (Pollard, 1997). Teachers should not adopt a static attitude; they should support and encourage a wider use of research-based practices, which, in turn, may offer incentive to discover innovative techniques to motivate learners and engage them more actively in the learning process (Richardson, 1990). In light of the above, this study endeavors to examine differentiated instruction and its implication in the teaching of oracy skills to young EFL learners.

\section{How Young Learners Develop Their Oracy Skills}

As Cameron (2001: 52) states, "young speakers between five-and ten-years lack awareness of how to cater for other participants in discourse, and are not very skilful in planning their talk". She also supports that "children up to age seven seem to blame themselves if they do not understand something said to them, rather than judging that what was said to them might have been inadequate" (Cameron, 2001: 52).

Based on the above, the maturation of students' social and cognitive understanding takes place at an older age, a fact which seems to have implications for foreign language use and learning. More specifically, when children are asked to participate in a conversation which is beyond their cognitive developmental stage, they are simply forced to repeat without understanding. Additionally, all young learners are not ready to produce speech at the same time and pace. According to Vygotsky (1986), some children go through a silent period during the acquisition of their L1. This is a period when they listen to the language around them and internalize it before they form patterns in their zone of proximal development, a process which could also apply to the acquisition of L2.

Familiarity with content and context in foreign language tasks is also helpful. Cameron (2001: 53) advocates that "discourse in young learner classrooms should follow patterns children find familiar, from their home and family, or from their school experience, and should not demand more of children than they can do". Since many course books contain tasks and topics which may be difficult for some learners to cope with, the teachers should differentiate their instruction in order to make them comprehensible.

Although the existence of a silent period in L2 learning is not commonly accepted by all researchers, it is generally admitted that extensive listening practice, in the early stages of learning, helps learners to produce language at later stages. As Phillips (1993) suggests, activities based on the Total Physical Response are useful teaching techniques in primary 
classes, as, by listening to what the teacher says and following their teacher's instructions, the learners' ability to understand is maximized.

While learning their first language, children are exposed firstly to aural stimuli before they try sounds and produce language. Children's receptive skills develop before their productive skills (Krashen, 1982) and this is a process followed throughout their education. Therefore, it makes sense for teachers to pay special attention to listening tasks which provide the context for use of non-verbal support, such as visuals, mime or movement so that foreign language skills are successfully developed.

Children also expect to be able to speak in the foreign language as soon as possible, in order to communicate (Brewster et al., 1992), so they should be given opportunities to speak as much as possible, to retain this early motivation and retain their enthusiasm for learning. Since children enjoy 'playing' with language in their mother tongue (for example by using songs, rhymes and riddles), it is obvious that their keenness for games could also be transferred to the foreign language classroom. Creating or adapting activities in order to make them more playful gives children the opportunity to learn in a more effective and enjoyable manner, since as Bruner (1978: 96) points out, "play is the business of childhood".

Children usually pick up and use quite long and complex phrases and sentences very easily and quickly, so the teacher, who is also considered to be the facilitator between the foreign language and the mother tongue, can adopt these practices, to facilitate learning. Yet, it is important for teachers to make decisions about the language to be used in their classrooms, depending on the learners' abilities and needs and their general context which includes factors such as the curriculum or the school policy.

\section{The Aim and Research Questions of the Study}

The aim of this study is to investigate and present the effectiveness of differentiated instruction in order to motivate young learners in acquiring basic knowledge of the English language and to enhance their oracy skills. The teaching is based on the principles of the Common European Framework of Reference (CEFR), which is basically the 'curriculum' which is implemented in private language centers. More specifically the CEFR describes six broad levels of ability, starting from A1 which is the lowest and reaching C2 which is the highest level. Learners are categorized into three groups: The Basic User (levels A1 and A2), the Independent User (B1 and B2) and the Proficient User (C1 and C2). According to these levels, learners develop not only in terms of the actual language they have acquired, but also in terms of their communication strategies. The teachers who are also the researchers formed a hypothesis that the suggested teaching techniques would help students, of the specific age and language level, to perform better, as opposed to those students who followed the conventional book-based methods. They also hoped that the proposed study would pave the way for teachers to adapt and implement activities not only in the private sector, which deals with smaller groups of students, as is the case of this particular research, but in the public sector as well, which addresses larger groups of students. In this vein, a major research question has been set:

- How can differentiated instruction be employed in the language classroom in order to enhance students' oracy skills? 


\section{Macrothink

Followed, by specific sub-questions, namely:

- To what extent can oracy skills be practiced through differentiated instruction?

- What problems arise during the application of differentiated instruction?

- What is the teachers' attitude towards differentiated teaching?

- What is the teacher's attitude towards oracy development?

- How do young learners respond to differentiated instruction?

- Can differentiated instruction enhance students' oracy development through a task-based pedagogical intervention?

- What should be taken into consideration before placing differentiated instruction approaches into practice?

An effective way of collecting reliable data in order to answer to the above research questions was by using audio recordings. Another means for gathering qualitative data was that of the teacher's journal. Semi-structured interviews were also used as a means of triangulation in this multi-method research. Of course, all the interviews were recorded and transcribed in order to compare the students' responses.

\section{Methodology}

The researchers have chosen to tackle differentiated instruction through a case study, which is a subordinate to action research, as it is useful to test theoretical models by applying them in real life situations. Since a case study is an in-depth analysis of a particular situation, it will give indications of the learners' progress and allow for a 'hypothesis' creation and further elaboration upon the subject (Gerring, 2011). Thus, two groups of students, the control group and the experimental group, participated in this action research. The main advantage of this method is that you can focus on specific and interesting cases such as problem-solving and decision-making activities.

To triangulate the data, a mixed-methods design with quantitative and qualitative analyses was used. Data was collected through semi-structured interviews, which were directed to the students of the experimental group (Drever, 1995). Finally, the data that was collected was classified into a manageable form and constructed in the form of a narrative in order to present the results. Dornyei (2007) illustrates that the intention of qualitative research is to gather and explore the participants' attitudes towards the situation being studied. In the same vein, Duff (2008) claims that qualitative research does not account for one interpretation but it rather ventures multiple interpretations of human experience. Taking into consideration that the sample population involved in the particular research was small, Dornyei (2007: 126) reports that,

Qualitative research is not concerned with how representative the respondents' sample is but it rather aims at finding individuals who can provide rich and varied insights into the phenomenon under investigation so as to maximize what we can learn.

Qualitative data could also be collected from recorded interviews, observations during the actual teaching of the lessons, field notes and photos, all of which aim at achieving a richer description of the process (Dornyei, 2007).

The researchers believe that it is very important for EFL teachers to see their classroom 
practices under a multidimensional perspective (Bolhuis, 2003). Language learning needs to have content and meaning and mainstream curriculum teaching should take into consideration the language needs of the learners. For this reason, the teachers carried out a research on their own teaching context, in order to help students, enhance their oracy skills, through the implementation of a task-based framework. The integration of the basic theories on oracy skills will be practiced in a more communicative manner. There is also an attempt to provide valuable feedback on the tasks and the activities which motivate learners and help them to develop their oracy skills. The observation of the two groups of students will show the similarities and/or differences on students' performance, given that the experimental group will participate in a series of specially designed lessons. This comparison between the groups will hopefully provide insights into how students can learn more effectively and what can help them overcome their weaknesses.

\subsection{Action Research Approach}

Since the researchers acted as investigators of their own teaching context, the mode of investigation employed in this particular study was based on action research. According to Burns (2010: 2), action research is related to the ideas of "reflected practice and the teacher as researcher". More specifically, she states that in action research, the teachers explore their personal contexts more systematically in order to improve their teaching practices. Action research is an excellent means for teachers to reflect on their own practices. As Ferrance (2000: 15) successfully points out, "opportunities for teachers to evaluate themselves in schools are often few, and usually happen only in an informal manner" thus, "action research can serve as a chance to really take a look at one's own teaching in a structured manner".

\subsection{Case Study}

The particular research is also characterized as a case study, which is a subordinate to action research, since it focuses on a single instance (Gerring, 2004). Thus, in this specific case, the participants were divided into two classes of beginners. They all attended a private language center in the town of Aridea, in Greece.

A case study has many advantages for both the participants and the researcher. One of their benefits is the ability to capture what Hodkinson and Hodkinson (2001: 3) call "lived reality". As they suggest, case studies have the potential, when applied successfully, to "retain more of the 'noise' of real life than many other types of research" (Hodkinson \& Hodkinson, 2001: 3). Case study research is more than simply carrying out a research on a single individual or situation. As Baxter and Jack (2008: 556) argue "this approach enables the researcher to answer 'how' and 'why' type questions, while taking into consideration how a phenomenon is influenced by the context within which it is situated". For an inexperienced researcher, a case study is an excellent opportunity to gain insight into a case as it offers the potential to gather data from a variety of sources and to utilize them in the best possible way.

\subsection{Experimental Design}

As part of the action research procedure, this study also adopts an experimental research design involving differentiated instruction for a period of ten weeks. Since there were some practical constraints which had to do with the owner's reservations, as regards the parents' attitude towards the differentiated instruction which would be followed, the researchers had 
to limit the duration of differentiated instruction to 10 weeks instead of 12 which was initially planned. In the particular context, one group, which was designated as the control group, was taught through a conventional coursebook following the syllabus of the particular private language center, which was aligned to the specific age group and language level, while the second group, which served as the experimental group, was given the chance to practice through differentiated teaching techniques like pair or group-work activities and games.

\subsection{Description of the Teaching Context and the Learners' Profile}

The classes being described are two groups, each of which is composed of eight pupils, aged between 8 and 10. They belong to the A1 level of the Common European Framework, also known as the CEFR in short (Council of Europe, 2001). It is a monolingual class which belongs to the Kachruvian expanding circle, which means that it is within the periphery-EFL (Kachru, 1985). According to Kachru's (1985) categorization, we can interpret all international English language teaching situations in terms of three concentric circles. Every teaching situation around the world can be placed in one of these circles. The pupils come into contact with the L2 mainly in class and their hourly lessons take place once a week. Thus, they learn English in an instructional setting, where the target language is extensively used to ensure sufficient exposure to the foreign language. Yet, sometimes the learners' mother tongue is also a resort, as a device to overcome difficulties or just save valuable time.

Like any society, schools have their own identity, social character and unique values. Since the case here is a private language center, the principal is the authority who makes significant decisions mainly about books, facilities and equipment supporting education or more importantly, about the ideology of the school. Yet, the teaching staff will also play an instrumental role as they decide on how learning can be achieved. The profile and the identity of the school is also influenced by the pupils' parents and their overall stance towards learning. Unfortunately, in most of the cases parents insist on the importance of certificates, which forces the school to use specific exam-oriented techniques and materials in order to ensure success.

On the other hand, a major advantage of the school is the learning environment. The building is big and well-equipped with all the latest technology. Its bright walls and colorful posters provide pupils with an enjoyable environment and the fact that classes consist of a maximum of nine students create good conditions for learning.

Even though the course book is selected by the principal, the teachers are given the freedom to select additional resources and materials and have constant access to computers. As far as the coursebook is concerned, it is a recently published book called 'Smiles' which, through the learning principles and the educational ideologies it supports, it follows the guidelines of the CEFR for A1 level users.

\subsection{Description of the Book-Based Context}

Before presenting both the traditional and the experimental procedure, it should be mentioned that the study took over a period of ten weeks to be completed. It consisted of ten lessons for each group which lasted for forty-five minutes each. Both groups were taught based on the coursebook selected by the private language centre. Yet, the control group was engaged only in a traditional, book-based methodology following the lesson plans presented in the 
Teacher's Book and syllabus, while the experimental group was taught through differentiated instruction.

\subsection{Differentiated Instruction Through an Experimental Procedure}

The second group (also known as the experimental group) was taught through differentiated instruction which included different activities such as games that were used in order to enhance the learners' oracy skills. The lesson plans which were followed in the experimental group were varied. More specifically, some activities were adapted and some others were replaced by games so as to make the lesson more effective and enjoyable. For instance, the first lesson explored the topics of appearance and family members. The game which was used was 'Questions on a stick' and it needed a jar, some colored cardboard sticks and some candies. The students had to answer specific questions according to the sticks they had chosen. The lessons were recorded with the permission of the school director and the students' parents, since the researchers felt the need to have constant access to the entire teaching procedure. Additionally, they kept a teacher's journal after each session with both the control and the experimental group.

A pre-test was given to both the control and the experimental group (the contents of which were the same for both groups) so as to check their knowledge and diagnose their needs. More specifically, the pre-test needed about 20 minutes to be completed for each group and it was an oral test to assess students' abilities and needs. While the students were answering the questions, the teachers were taking notes in their journals in order to make sure that the classes were homogeneous. Furthermore, after the end of the ten lessons, a post-test was given to both groups (the contents of which were - also - the same for both groups) to check their progress. The results were obtained through the notes of the teachers' journals. The researchers also carried out one-to-one semi-structured interviews and transcribed them to acquire descriptive data through the students' responses.

\subsection{Tools for Data Collection}

In this section, a detailed description of both the qualitative and the quantitative instruments employed to collect data for this research are presented.

\subsubsection{Qualitative Data Tools}

According to Mack et al (2005: 1), "the strength of qualitative research is its ability to provide complex textual descriptions on how people experience a given research issue" and "it provides information about the 'human' side of an issue - that is, the often-contradictory-behaviors, beliefs, opinions, emotions, and relationships of individuals". In this particular research the teachers who were also the researchers collected data through recordings, journals and semi-structured interviews.

\subsubsection{Audio Recordings}

An effective way of collecting reliable data is by using audio or video recordings. Recording the whole teaching process provides you with constant and direct access to your data. As Rapley (2007: 50) wrote,

The actual process of making detailed transcripts enables you to become familiar with what you are observing. You have to listen/watch the recording again and again. [...] Through this process you begin to notice the interesting and often subtle ways that people interact. These are 


\section{Ml Macrothink}

the taken-for-granted features of people's talk and interaction that without recordings you would routinely fail to notice, fail to remember, or be unable to record in sufficient detail by taking hand-written notes as it happened.

Since this research is about very young learners, the teachers/researchers had to hand out cover letters to all the parents in order to assure them that the recordings would be used only for the purposes of the specific research. Perhaps a video recording would be a better solution in order to depict the students' emotions and reactions, but the owner of the language center granted permission only for audio recordings.

\subsubsection{Teacher's Journal}

Another means for gathering qualitative data is that of the teacher's journal. As Michelle Ortlipp (2008: 700) wrote about journals:

I wrote in order to learn and to understand issues around methodology so that I could settle on a way of conducting my research and justify my decisions. I began to see the relevance and suitability of this reflective writing process for the way I was conceptualizing my study and enacting my research as an individual with particular personal experiences, desires, and ways of looking at the world. Reflective journal writing enabled me to articulate my ideas about conceptual frameworks for analysis of the data and led me eventually to reject an interpretivist-constructivist framework.

Given the fact that all the teaching sessions of both groups had been recorded, as was previously discussed, the teachers who were also the researchers were able to continually reflect on the audio material and keep track of their journals.

\subsubsection{Semi-Structured Interviews}

In this particular research, the researchers opted for semi-structured interviews as "they are probably still one of the most commonly used qualitative methods" (Kitchin \& Tate, 2000: 213). Furthermore, semi-structured interviews can be used as a means for triangulation in a multi-method research.

The purpose of the specific semi-structured interview was to investigate the ideas of the eight interviewees of the experimental group in a simple conversational style as regards the implementation of the games and their impact on them through open-ended questions. By using open-ended questions, the researchers strongly believed that they provided the students with more flexibility so as to receive more spontaneous answers. All the interviews were recorded and transcribed in order to compare the students' responses.

\subsubsection{Pre-tests and Post-tests}

As Dimitrov and Rumrill (2003: 159) support "pretest-posttest designs are widely used in behavioral research, primarily for the purpose of comparing groups and/or measuring change resulting from experimental treatments". The teachers decided to use a pre-test before the beginning of the lessons which was given to both groups so as to assess if all the students are of the same language level (see section 5.1 of this research paper for the quantitative data) and a post-test after the end of the 10 lessons in order to verify if there has been any improvement in their performance (see section 5.2 of this research paper for the quantitative data). 


\subsubsection{Description of the Pre- test}

The pre-test needed about 20 minutes to be completed for each group (as the content of the pre-test was the same for both groups) and it was an oral test to assess students' abilities and needs. While the students were answering the questions, the teachers took notes in order to make sure that the classes were homogeneous. The pre-test was composed of listening and speaking tasks as the aim of the specific research was to investigate the learners' oracy skills. The first activity included some personal questions addressed to the learners by the heroes of their course book (e.g. What's your name? /How old are you? / What's your best friend's name? etc.). The second one was a pair-work activity as students had to ask questions and also had to prompt their partners to answer these questions (e.g. When's your birthday? / What's your favorite football team? etc). During the third activity the students had to listen carefully to their teachers in order to number the clothes of the pictures in the order in which they heard them.

\subsubsection{Description of the Post -test}

After the completion of the teaching procedure, a final post-test was given out to both groups (the content of the post-test was the same for both groups) in order to determine and compare the level of oral/aural development of the two groups in comparison to the results of the initial pre- test. The particular test had the same format as the pre-test and the teachers also kept notes as in the pre-test.

\section{Results}

In this chapter an attempt is made to see whether the students of the experimental group have developed their oracy skills in comparison to the students of the control group, who attended lessons which were based only on their coursebook. The qualitative data which was collected through the students' responses during the semi-structured interviews provided the researchers with useful insight into the students' opinions and were constructed in the form of a narrative so as to triangulate this research. Finally, the data that was gathered was used to provide answers to the research questions, to reveal the limitations of this study and to make suggestions for further research.

\subsection{Analysis of the Pre-test}

The pre-test was given to both groups before the beginning of the experimental process. The main purpose of this was to ensure that the two groups of students were at the same language level and did not present any striking differences. As it was proved from the first contact session with the two groups of students, there weren't any significant differences between the performance of the two groups, regarding their language level competence. In the control group, $38 \%$ of the students who participated, did well and seemed willing to take part, while in the experimental group $50 \%$ of the students had a similar attitude.

More specifically, most of the students $(88 \%)$ remembered the heroes of the coursebook (Liam and Lilly) from the previous year, since they were taught through a similar series of books (Smiles for Junior A), thus they seemed willing to answer the introductory questions concerning their name, age, friends, siblings and free-time activities (e.g. What's your name? /How old are you? / What's your best friend's name? etc.). Yet, although they understood the questions, $63 \%$ of the students of the control group and $50 \%$ of the students of the experimental group seemed hesitant to answer all of them because they did not want to lose 
face in case they made a mistake.

In the second task of the pre-test, which was a pair-work activity as students had to ask questions and get their partners to answer, the students had many difficulties in forming questions and addressing their partners. In the control group, $88 \%$ of the students and in the experimental group, $75 \%$ of the students, did not seem able to carry out this activity. As a result, the teacher had to help them and lead them in order to encourage them to express themselves freely.

Additionally, most of the students (75\% of the students of the control group) seemed to have forgotten the English words needed for the third activity, during which the students had to listen carefully to their teacher in order to number the clothes in the order in which they heard them, or at least they had some doubts as to whether they were completing the task correctly (75\% of the students of the experimental group).

\subsection{Analysis of the Post-test}

The post-test, which was of the same content as the pre-test, was given to both the control and the experimental group after the completion of the 10 -week period. The main purpose of this was to check whether there would be any differences regarding the performance of these two groups, given that they were taught through different methods.

The results of the post-test revealed that the experimental group made great progress in comparison to their initial performance in the pre-test as all students (100\% of the students) understood the questions and were able to answer them without any hesitation. They also showed great willingness to complete the tasks of the post-test as they raised their hands and seemed impatient to wait for their turn.

On the other hand, though, the students of the control group did not perform much better than they did during the pre-test, as only one student seemed to improve. Twenty-five $(25 \%)$ of the students exhibited some improvements mainly in the introductory questions about themselves during the first task but overall their performance was not very satisfactory. Most of them (75\%) did not seem motivated to answer the questions and they seemed embarrassed, especially when they had to address their partners during the second task. As a result, the teacher had to support and help them throughout the whole procedure.

Furthermore, unlike the experimental group, the majority of the control group (88\%) showed great difficulty in producing their own authentic speech and preferred to use prefabricated chunks of language which they had either memorized during their lessons or listened to previously from some of their partners.

Therefore, it can be concluded that the experimental group has surpassed both their initial performance and that of the control group, a fact which may be attributed to the effects of the differentiated techniques that were employed during the teaching procedure of the 10 -week lesson period.

\subsection{Findings and Analysis of the Semi-structured Interviews}

The data which emerged from the semi-structured interviews of the experimental group was transcribed and analyzed through an axial coding procedure where all information was pieced together, organized and categorized. 


\section{$\Lambda$ Macrothink}

\subsubsection{The First Axis}

The first axis revolved around the students' answers which asked whether they liked the proposed games and the reason why they did so. The findings showed that all the students (see Figure 1) enjoyed the fact that they played games in the classroom. All of them said that this was because they found the particular games very entertaining, as they played with their friends, had fun and learnt a lot of useful things at the same time (Figure 2). What is more, it is worth mentioning that one student revealed that he liked the fact that they were playing in the classroom, instead of having lessons, verifying the hypothesis that students become highly motivated to learn English through games.

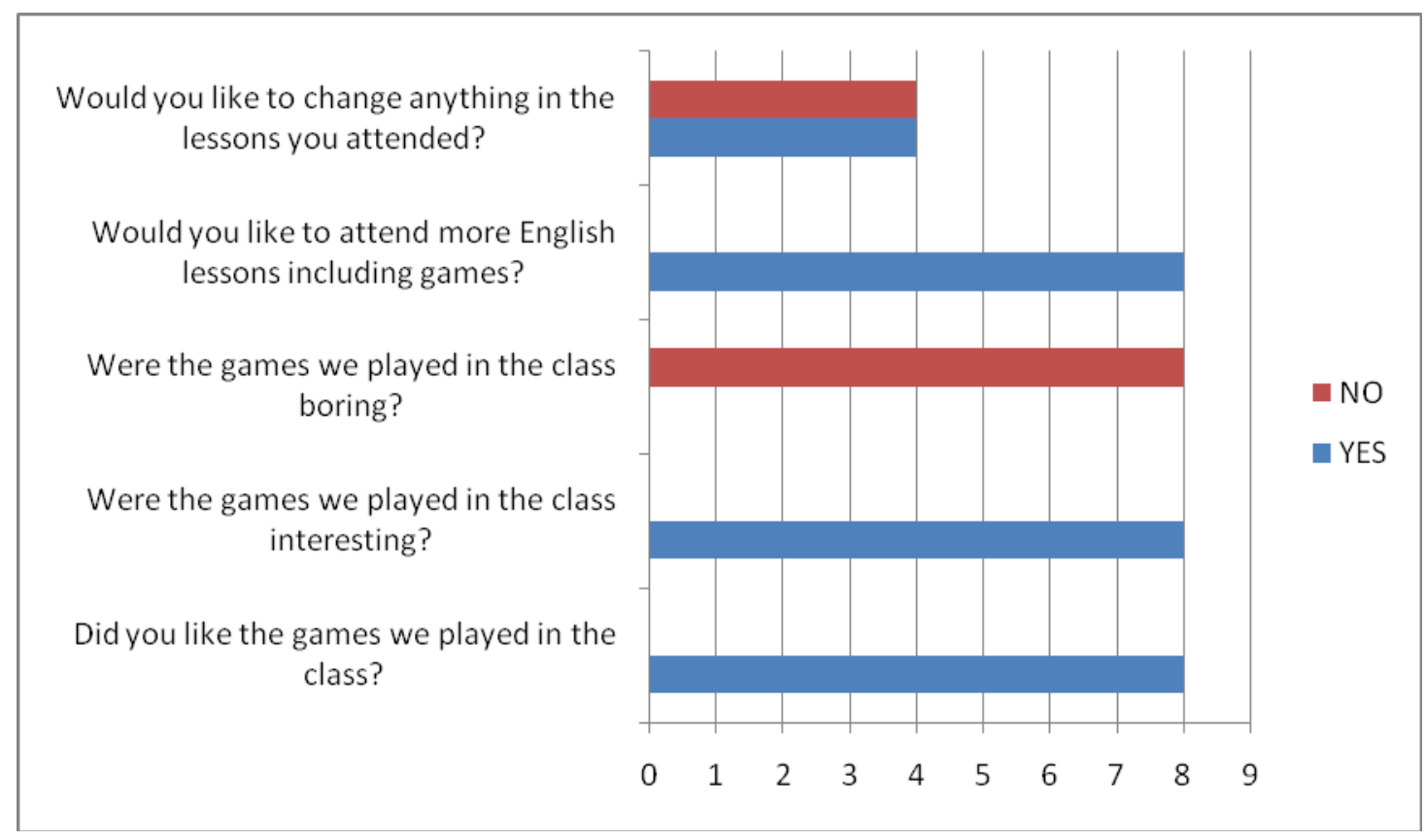

Figure 1. Students' answers on the questions of the semi-structured interviews

\subsubsection{The Second Axis}

As far as the questions of the second axis were concerned, in other words the questions on whether the games were interesting or boring, all the students agreed that the proposed games were interesting (see Figure 1) because they (the students) were not bored with them (meaning that they were not bored with the games); instead they had fun all together because the games engaged them in fun learning. The purpose of the rest of the questions of this axis, where the students were asked whether they liked each of the proposed games a little, a lot or very much was to elicit valuable feedback on the students' preferences. Their responses indicate that their favorite was the game 'Detect the spy' (see Table 1), probably because it involved physical action, as well as a variation of the game 'Noughts and Crosses' which was already familiar to them. On the other hand, the games which they liked the least were 'Find Simon' and 'Find the time' which they probably thought were the most difficult or boring of all. 


\section{Macrothink}

Table 1. Description of the game 'Detect the spy'

Aim: to motivate Learners to listen to specific information and revise vocabulary related to physical appearance and clothes.

Preparation: The teacher has to arrange the chairs in a semicircle in front of her.

a. Procedure: The teacher explains the instructions of the game.

b. The teacher has all the students stand up and explains that they are going to hear statements that describe different details of a spy (a student that the teacher has chosen). If a detail does not apply to them, they have to sit down. For example, if the teacher says 'The spy is a girl', all the boys have to sit down.

c. The teacher can have the sentences all affirmative, all negative or a mixture of both e.g. 'The spy is not wearing a blue sweater'.

d. The last student who stands still is the spy.

e. Continue as long as interest is high.

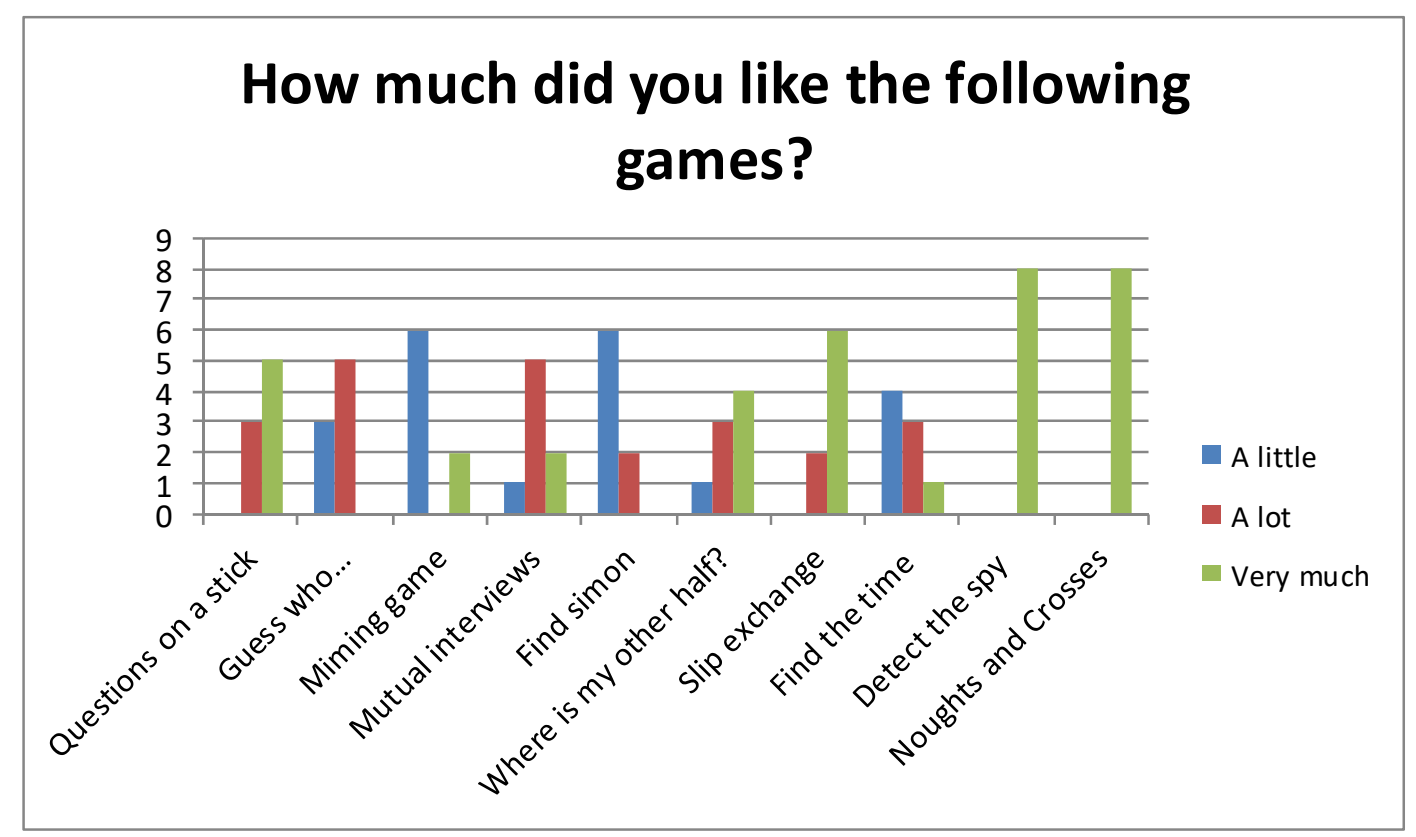

Figure 2. Students' preferences regarding the games

\subsubsection{The Third Axis}

Finally, the last axis of the questions investigated the students' experiences in terms of the way the specific games helped them to learn new things. All the students agreed upon the same fact that through these games, they were given the chance to see, remember, name and repeat the target items many times in a playful context, which resulted positively in the students' learning competence as opposed to the students who followed the traditional coursebook-based method. They had the chance to memorize everything more easily and quickly, since there was a lot of repetition both by the teachers and by the students in an 
entertaining manner and they also thought time passed quickly. Furthermore, the interpretation of the findings obtained from the specific students' responses is in line with the theory which suggests that games prompt cooperation. As Pinter (2006) states, with age, children begin to approach language more analytically and, having started school, they develop their literacy skills and some degree of awareness of language structure and form which shows that they begin to organize their learning, they become less egocentric and more willing to cooperate and/or compete. All the students who participated in the experimental group $(100 \%)$ seemed enthusiastic about games as they all wanted to take part in more lessons including games (see Figure 1). Half of them (50\%) thought that the lessons were very pleasant and they would not change anything in them, while the rest stated that they would prefer more games or even only games instead of the traditional book-based exercises. Finally, one of the students also noted that he would like to follow the same procedure at school, too.

\section{Limitations of the Study and Suggestions for Further Research}

The purpose of this study was to determine whether differentiated instruction including games could help young students to enhance their oracy skills in relation to topics which are appropriate for their age group and language level. The participants were very motivated towards the use of the adapted games (see also Gerovasiliou \& Zafiri, 2017) and thought that they contributed to their learning. However, there were a number of limitations to be considered.

First of all, there were some difficulties which had to be overcome on behalf of the owner of the private language center where the research took place. She was very dubious and worried about the parents' reactions to the application of differentiated instruction and to the use of video-recordings which was the initial plan. As a result, the teachers who were also the researchers used only audio-recordings and assured the parents that the transcripts would be used only for the particular purpose of this study. The parents agreed and granted their permission.

Another problem is that the findings of this study are restricted because of the small number of participants. Due to the fact that only sixteen students took part in the research, it means that the findings of this study cannot be generalized and applied to all teaching contexts. As a result, it cannot be argued that the particular sample represents all students of the particular age group, although it is a satisfying sample if we take into consideration the fact that the research took place in a small provincial town.

Furthermore, the students were very young and it was the first time that they had participated in an interview. Due to this fact, the teachers felt that the students were not as productive as they had hoped even though the semi-structured interview was designed with the use of simple language so as not to confuse students. Sometimes they seemed to be hesitant before answering and some of them preferred to answer using one word only.

Yet, although only tentative conclusions could be drawn, even with such a small sample, the particular study contributed to the body of knowledge regarding the effectiveness of using differentiated instruction to enhance students' oracy skills. All things considered, it is suggested that future studies should be conducted, to include a more representative sample so 
as to provide an in-depth analysis on students' performance regarding the improvement of their oracy skills.

\section{Conclusion}

Many students, especially of a very young age, as was the case of the students of this particular research, think that listening and speaking activities are very difficult as they are not exposed to spoken language very often. Additionally, most of the parents have a negative attitude towards 'playful' (as they call them) tasks, as they believe that a lesson should only consist of reading and writing tasks. Taking these beliefs into consideration, the teachers who were also the researchers, tried to examine the effectiveness of differentiated teaching in the foreign language classroom amongst very young learners.

Although there were some limitations which have been referred to, in general, after a ten-week period, the particular differentiated instruction which included the adaptation of games (see also Gerovasiliou \& Zafiri, 2017), which considered the learners' age, language level and the principles of the syllabus and the curriculum, enhanced students' oracy skills and helped them to perform better in comparison to the students of the control group which followed the traditional book-based method. All of the participants were very enthusiastic about the differentiated activities and realized that it was a pleasant way to learn without being bored. Furthermore, they thought the activities were very motivating and in spite of the element of competition, all of them cooperated harmoniously by helping each other when somebody could not answer correctly.

Finally, all of them expressed their wish to continue learning the target language in the same way or even with more games. Therefore, differentiated instruction could be integrated in the language classroom since it gives students the chance for intensive practice in an interesting and enjoyable manner.

\section{References}

Baxter, P., \& Jack, S. (2008). Qualitative Case Study Methodology: Study Design and Implementation for Novice Researchers. The Qualitative Report, 13(4).

Bolhuis, S. (2003). 'Toward process-oriented teaching for self-directed lifelong learning: a multidimensional perspective'. In Learning and Instruction, 13, 327-347. https://doi.org/10.1016/S0959-4752(02)00008-7

Brewster, J., Ellis, G., \& Girard, D. (1992). The Primary Teacher's Guide. Harmondsworth: Penguin.

Bruner, J. S. (1978). The Role of Dialogue in Language Acquisition. In A. Sinclair, R. J. Jarvelle, \& W. J. M. Levelt (Eds.), The Child's Concept of Language.

Burns, A. (2010). Doing action research in language teaching: A Guide for practitioners. (1st ed.). ESL \& Applied linguistics professional series.

Cameron, L. (2001). Teaching English to young learners. Cambridge: Cambridge University Press.

Dimitrov. D. M., \& Rumrill, Jr, P. D. (2003). 'Pretest- posttest designs and measurement of change'. In IOS Press, 20, 159-165.

Dornyei, Z. (2007). Research methods in applied linguistics: Quantitative, qualitative and 
mixed methodologies. Oxford: Oxford University Press.

Drever, E. (1995). Using Semi-Structured Interviews in Small-Scale Research. A Teacher's Guide. Edinburgh: Scottish Council for Research in Education.

Duff, P. A. (2008). Case study research in applied linguistics. United States of America: Lawrence Erlbaum Associates.

Ferrance, E. (2000). Action research. LAB: Brown university.

Gerovasiliou, F., \& Zafiri, M. (2017). Adapting board games to stimulate motivation in vocabulary learning in six-year-old learners. A case study. Journal of studies in Education, 7(3), 1- 28. https://doi.org/10.5296/jse.v7i3.11323

Gerring, J. (2004). 'What is a case study and what is it good for'? In American Political Science Review, 98(2), 341-354. https://doi.org/10.1017/S0003055404001182

Gerring, J. (2011). The Case Study: What it is and What it Does. In The Oxford Handbook of Political Science:: Oxford University Press. https://doi.org/10.1093/oxfordhb/97801996 04456.013.0051

Hodkinson, P., \& Hodkinson, H. (2001). The Strengths and Limitations of Case Study Research. In Learning and Skills Development Agency conference, Making an Impact on Policy and Practice. Cambridge.

Kachru, B. B. (1985). Standards, codifications, and sociolinguistic realism: The English language in the outer circle. In R. Quirk, \& H. Widdowson (Eds.), English in the world: teaching and learning the language and literatures. Cambridge: Cambridge University Press.

Kitchin, R., \& Tate, J. (2000). Conducting Research into Human Geography: Theory, Methodology and Practice. New York: Pretence Hall.

Krashen, S. (1982). Principles and Practice in Second Language Acquisition. Oxford: Pergamon.

Mack N., \& Woodsong, K. (2005). Qualitative Research Methods: A Data Collector's Field Guide. Family Health International.

Long, M., \& Crookes, G. (1991). Three approaches to task-based syllabus design. TESOL Quarterly, 26, 27-55. https://doi.org/10.2307/3587368

Ortlipp, M. (2008). Keeping and using reflective journals in the qualitative research process.

In The Qualitative Report, 13(4), 695-705.

Phillips, S. (1993). Young Learners. Oxford: Oxford University Press.

Pinter, A. (2006). Teaching young language learners. Oxford: Oxford University Press.

Pollard, A. (1997). Reflective Teaching in the Primary School. London: Cassell Education.

Rapley, T. (2007). Doing Conversation, Discourse and Document Analysis. The Sage qualitative research kit. Thousand Oaks, CA: Sage publication. https://doi.org/10.4135/978 1849208901

Richardson, R. (1990). Daring to be a teacher. Stoke-on-Trent: Trentham Books.

Vygotsky, L. S. (1986). Thought and language. Cambridge, MA: MIT Press. 


\section{Macrothink

\section{Copyright Disclaimer}

Copyright reserved by the author(s).

This article is an open-access article distributed under the terms and conditions of the Creative Commons Attribution license (http://creativecommons.org/licenses/by/3.0/). 